\title{
Realizing Expectations from Planting Trees on Private Land in Ontario, Canada
}

\begin{abstract}
This study explores the motivations behind participation in tree planting programs by private landowners in Ontario, Canada, as well as perceptions as to whether benefits were realized up to ten years after trees were planted. Forests Ontario, which has offered tree planting support programs in this province since 2007, provides up to $90 \%$ of the cost of seedlings for tree planting projects at least one hectare (ha) in size. This online survey of $\mathbf{5 7 0}$ former participants in tree planting programs indicated that a desire to create a habitat for wildlife (77.6\%) was the most common motivation for taking part in a tree planting program. Concern with restoring native forest cover was also a reason for most participants (71.4\%), as well as with improving soil, air and water quality (54.8\%), and addressing climate change (54.3\%). The most common benefit of planting trees was an increase in well-being and enjoyment of their property ( $67 \%$ of respondents). Overall, $27 \%$ of respondents with a desire to increase wildlife habitat, and $20 \%$ of those wishing to improve their local environment reported an improvement after tree planting. Reported improvements in the local environment and wildlife increased with time since tree planting, whereas enhanced well-being and enjoyment of the property were evident among participants even with newly planted trees.
\end{abstract}

Heather MacDonald ${ }^{1 *}$, Daniel McKenney ${ }^{1}$, Kerry McLaven ${ }^{2}$, Suzanne Perry ${ }^{2}$

\footnotetext{
1) Great Lakes Forestry Centre, Canadian Forest Service, Natural Resources Canada, Sault Ste. Marie, Canada

2) Forests Ontario, Toronto, Canada

*Corresponding author: Heather MacDonald, Great Lakes Forestry Centre, Canadian Forest Service, Natural Resources Canada, Queen Street East 1219, P6A 2E5, Sault Ste. Marie, Ontario, Canada. Email: Heather.MacDonald4@canada.ca
}

\section{Keywords:}

tree planting, afforestation, wildlife, motivation 


\section{Introduction}

\subsection{Motivations for planting trees}

People plant trees for different reasons. Psychologically and physically, exposure to natural settings is restorative (Hartig, et al., 2003, Van den Berg et al., 2003) and improves human health, cognitive performance and well-being (Keniger, et al., 2013). National surveys completed in the United States suggest forest beauty, wildlife and nature protection are common reasons for owning private forests (Butler et al., 2004, Butler et al., 2016). Indiana landowners reported afforesting their property to provide for future generations, to support wildlife, and to conserve the natural environment (Ross-Davis et al., 2005). In Quebec, Canada, woodlot owners report being motivated by the pleasure of owning a natural environment, firewood harvest, legacy, and family activities, while a third of owners owned a woodlot to generate a second income (Côté, et al., 2015).

Of course, not all people want to plant trees on their property. For instance, one-quarter of eligible residents in Detroit, Michigan turned down free street trees (Carmichael \& McDonough, 2018) due to a history with unmaintained trees following the contraction of Detroit's tree maintenance program. Further, only one in five U.S. forest owners plant trees on their land (Butler, 2008). In Ontario, Canada, residential property owners reported factoring in maintenance concerns as well as aesthetics in tree planting decisions (Conway, 2016). These studies highlight the need to design tree planting programs in a way that is responsive to residents' motivations.

\subsection{History of tree planting in southern Ontario}

The forests of southern Ontario, Canada, were logged to provide timber for the British and French navies from 1776 to 1836 (Elliott, 1998). Later, settlement by Europeans in the $18^{\text {th }}$ and $19^{\text {th }}$ century resulted in widespread land clearing and draining of wetlands for agriculture (Butt et al., 2005). Tree planting efforts to restore such degraded areas began prior to the $20^{\text {th }}$ century in Ontario. Specifically, the Tree Planting Act of 1883 encouraged tree plant- ing next to public highways and between farms. Before 1900 , approximately 75,000 trees were planted (Ontario Ministry of Natural Resources, 2001).

Seedlings came from provincial tree nurseries, the first of which was established at the Ontario Agricultural College in Guelph in 1905 (Ontario Ministry of Natural Resources, 2001). As part of the Agreement Forest Program, the Ontario government entered into agreements for managing and reforesting land from more than 50 municipalities and other eligible land owners (such as conservation authorities). At the height of this program, over 100,000 hectares (ha) were covered by this program (Borczon, 1982). In 1994, agreements were migrated to arm's length conservation authorities and municipalities from the provincial government. The Ontario government reported that 147.5 million trees were planted under the Agreement Forests program from 1921 to 1998 (Ontario Ministry of Natural Resources, 2001). The Woodlands Improvement Act of 1967, which offered tree planting or woodlot management to property owners at a reduced tree cost, resulted in approximately 213 million trees planted. However, in 1994, these private land services were eliminated. Two smaller programs, Project Tree Cover and the Permanent Cover Program, ran for five and three years respectively in the 1990s which resulted in approximately nine million trees planted in total (Ontario Ministry of Natural Resources, 2001).

In the late 1990s and early 2000s, partly in response to the Kyoto Protocol, the Ontario government began looking at potential in the province for afforestation, defined as tree planting on land that had not been forested for 50 years (Cherry, 2001). A study in 1999 indicated that there were approximately 2.6 million ha of unforested land in agricultural land classes 3 (moderately severe limitations that restrict the range of crops or required special conservation practices) to 7 (no capability for arable culture) that could potentially be afforested (Arbor Vitae et al., 1999).

In August 2007, the Government of Ontario, Canada, introduced a plan to address climate change (Government of Ontario, 2007), which included the 50 Million Tree program (50MTP). As the lead delivery agent for the 50 Million Tree program, Forests On- 
tario (formerly Trees Ontario) covers up to $90 \%$ of tree planting costs for tree planting projects greater than one hectare in size. In return, land owners sign a 15-year management agreement for the trees. In total, over 6,000 tree planting projects have been completed as part of various Forests Ontario/Trees Ontario programs, and some 22 million trees have been planted (Forests Ontario, 2017).

\subsection{Goal of the study}

In this study, we hoped to discover the motivations and benefit realizations for tree planting projects initiated by private land owners in Ontario from 2007 to 2017. Specifically, we wished to examine:

1. Have property owners experienced improvements in their property or well-being since planting trees?

2. How much time after tree planting is required before respondent perceive improvements to their well-being, local environment or wildlife populations?

A previous article explored the reported reasons for applying to a tree planting program (MacDonald et al., 2018). However, this study included applicants who did not always complete a project. The current study reports on motivations for planting trees for private land owners up to ten years after participating in an afforestation project. As well, survey data were used to assess whether expected benefits are realized, as well as the extent to which perceived impacts of planting were related to sapling age.

\section{Methods}

A 20-question survey was devised for administration in Survey Monkey (www.surveymonkey.com) with property owners that completed an afforestation project. The survey repeated wording from the intake survey. Survey respondents were asked what motivated them when they initially planted trees, including: legacy to descendants; future income; shade; local environment protection (e.g., soils, air and water); mitigation of climate change; restoration of native forest cover; and wildlife habitat enhance- ment. Landowners were asked if they perceived any changes to their well-being or enjoyment of their property, in wildlife, or with respect to the local environment, since planting trees. Finally, respondents were asked if their property was classified as farmland, as well as demographic questions including age, income and gender of respondent. The survey instrument is provided in Appendix 1.

Administrative data consisting of 6,245 tree planting projects were used to develop a list of email addresses for survey administration. Of the 4,928 unique first name-last name combinations, 2,216 had email addresses. On February 20, 2018, emails were sent to these 2,216 email addresses; of these, 29 email addresses were invalid (1.3\%). Surveys were completed between February 20 and March 5, 2018. A total of 570 respondents completed the survey, reflecting a response rate among participants with emails of $25.7 \%$, and representing $11.6 \%$ of all former participants. This response rate compares to 34 to $40 \%$ for published internet-based surveys (Cook, et al., 2000). By comparison, a recent mail-out survey with Indiana property owners about tree planting achieved a valid response rate of $28.8 \%$ (Ruseva et al., 2015).

Typically surveys completed online only are not as representative as mail plus online (Messer \& Dillman, 2011). In order to assess the representativeness of the survey data, program administrative data on year of participation from Forests Ontario were linked and compared to the survey data with respect to year of participation. A weighting adjustment was used in order to correct statistically significant differences between the survey sample and administrative data relative to available administrative data. Weights were calculated using the following formula:

$$
W_{i}=\frac{N_{i}}{N} / \frac{n_{i}}{n}
$$

where $W_{i}$ refers to the weight applied to each survey response for the $i^{\text {th }}$ year of participation, $N_{i} / N$ identifies the proportion of the population (administrative data) falling into category $i$, and $n_{i} / n$ refers to the proportion of survey responses at the $i^{\text {th }}$ year of participation. 
Chi-square tests of significance were requested in SAS (PROC FREQ) for analyses of categorical data including the following: a) motivations reported by gender, age, and farmland ownership; b) weighted versus unweighted motivations; and c) program effects on wildlife and the local environment by reported objective. Every survey question was compared across gender, age, and farm-ownership; statistically significant results using $\alpha=0.05$ are described in the text.

A logistic regression analysis was performed using PROC GENMOD in SAS Version 9.4 of the SAS System for Windows using participants from 2007 to 2017. A Generalized Estimation Equation (GEE) model for correlated response data was fit with respondent as the unit of analysis ("REPEATED" statement in PROC GENMOD). The dependent variable was a binary variable identifying whether the participant reported an improvement in wildlife, local environment and well-being since planting trees. Binary independent variables were used to indicate whether the benefit pertained to a) well-being or b) wildlife; improvements in the local environment were indirectly incorporated into the model, defined as an absence of a) or b). Years since planting (TreeAge) was a between-subject independent variable. Interaction terms between TreeAge and type of benefit were also included in the regression model. Model predictions were assessed by comparing model predictions to observed values of the dependent variable.

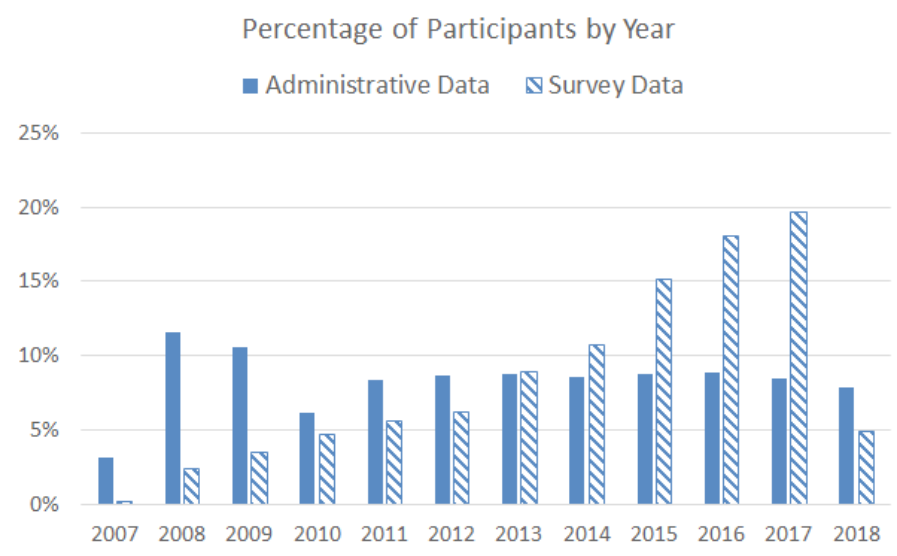

Figure 1: Participation in Forests Ontario Tree Planting Programs by year: administrative data $(n=6,238)$ versus survey respondents $(n=514)$
A number of pre-processing steps were implemented prior to data analysis. Because of the small number of respondents in tree age class 10, we grouped respondents with trees of nine or ten years in age together. Also, if respondents indicated that they did not know whether a change had occurred, these responses were recoded into the "no change" group of respondents. While there were a small number of self-reported absentee owners, this was not formally captured as part of the survey; further, a review of survey responses indicated that "don't know" responses were provided in cases where no change had been observed.

\section{Results and Discussion}

\subsection{Survey representativeness}

Survey respondents were more likely to have planted trees in the last five years compared to the administrative data, indicating that the email sample was biased in terms of participation date (see Figure 1 and Table 1). There were only thirteen survey respondents who participated in 2007 or 2008. A review of the administrative data suggests that few early participants had email addresses on file. For instance, out of the 189 participants in 2007, only 21 records contained email addresses.

Table 1: Counts, percentage of respondents, and calculated weights by year of participation

\begin{tabular}{|r|r|r|r|r|c|}
\hline \multicolumn{3}{|c|}{ Survey Data } & \multicolumn{2}{c|}{$\begin{array}{c}\text { Administrative } \\
\text { Data }\end{array}$} & Weight \\
\cline { 1 - 5 } Year & Count & $\%$ & Count & $\%$ & \\
\hline 2007 & 1 & $0.2 \%$ & 189 & $3.1 \%$ & \multirow{2}{*}{5.83763} \\
\hline 2008 & 12 & $2.3 \%$ & 701 & $11.6 \%$ & \\
\hline 2009 & 18 & $3.5 \%$ & 640 & $10.6 \%$ & 3.031778 \\
\hline 2010 & 24 & $4.7 \%$ & 373 & $6.2 \%$ & 1.325218 \\
\hline 2011 & 29 & $5.6 \%$ & 506 & $8.4 \%$ & 1.487793 \\
\hline 2012 & 32 & $6.2 \%$ & 523 & $8.7 \%$ & 1.393611 \\
\hline 2013 & 46 & $8.9 \%$ & 527 & $8.7 \%$ & 0.976883 \\
\hline 2014 & 55 & $10.7 \%$ & 518 & $8.6 \%$ & 0.803077 \\
\hline 2015 & 78 & $15.2 \%$ & 529 & $8.8 \%$ & 0.578297 \\
\hline 2016 & 93 & $18.1 \%$ & 537 & $8.9 \%$ & 0.492358 \\
\hline 2017 & 101 & $19.6 \%$ & 511 & $8.5 \%$ & 0.431409 \\
\hline 2018 & 25 & $4.9 \%$ & 474 & $7.9 \%$ & 1.616695 \\
\hline Total & 514 & $100.0 \%$ & 6028 & $100.0 \%$ & \\
\hline
\end{tabular}


Survey responders and all afforestation program participants were significantly different in terms of year of participation $\left(\chi^{2}=218.62, p<.0001\right)$. Because of the bias identified among survey respondents, we applied weights to survey responses by year of participation (detailed in Table 1) to the analysis of motivations for planting trees. Both weighted and unweighted results for each motivation are presented in Section 3.2.

Demographic characteristics of afforestation program participants were not tracked in the administrative database. Based on the survey results, approximately half of afforestation participants reported that their property was farmland (45.9\%). Most survey respondents were 55 years of age or older $(59.8 \%)$, compared to $16.9 \%$ that were 30 to 44 years of age, and $22.2 \%$ that were 45 to 54 years of age. Finally, more men (71.0\%) than women responded to the survey.

\subsection{Reasons for planting trees}

Both weighted and unweighted frequencies for each motivation are presented in Table 2 below. Despite there being statistically significant differences in the percentage of respondents by year of participation, weighted versus unweighted reasons for participating in the program were not statistically different. As a result, unweighted percentages are used in the text.

The most common reason recalled by respondents for planting trees was to create habitat for wildlife (73.5\%). Eighty percent of women and seventy percent of men were motivated by wildlife habitat restoration $\left(\chi^{2}=5.42, p=0.02\right)$. Farm owners were more likely to plant trees to enhance wildlife habitat $(79.3 \%)$ compared to other land owners $\left(68.5 \%, \chi^{2}=\right.$ $8.46, p=.004)$.

Overall, restoration of native forest cover was important for $69.6 \%$ of survey participants. Respondents aged fifty-five and older were significantly more likely to value restoring native tree cover $(75.9 \%)$ compared to younger land owners $\left(61.8 \%, \chi^{2}=13.14\right.$, $p=0.0003$ ).

Improving the local environment (soil, air and water quality) was a motivation for $51.5 \%$ of respondents. Those respondents whose property was classified as farmland were more likely to report improving the soil, air, and water quality as a motivation $(58.6 \%)$ compared to other owners $\left(45.5 \%, \chi^{2}=9.81\right.$, $p=.002$ ). Individuals aged fifty-five and older were statistically more likely to want to improve their local environment $(55.9 \%)$ compared to younger respondents $\left(46.1 \%, \chi^{2}=5.42, p=.02\right)$.

Concern about climate change inspired tree planting for about half of respondents (49.0\%). Climate change was reported as a motivation more among respondents aged $55+(56.2 \%)$ compared to younger respondents $\left(40.2 \%, \chi^{2}=14.46, p=0.0001\right)$. Women described climate change as a motivation for planting trees more often than men $(57.3 \%$ versus $46.1 \%$, $\chi^{2}=5.62, p=0.02$ ).

The goal of adding shade, a windbreak or buffer was also a reason for planting trees for about half of participants that answered this question (48.7\%). Farm windbreaks and shelterbelts can reduce energy losses of livestock and improve crop yields (Ontario Ministry of Natural Resources, 2001). As a result of such agricultural considerations, we investigated whether

Table 2: Weighted and unweighted percent of respondents reporting each reason for planting trees, including $\chi^{2}$ scores and p-values.

\begin{tabular}{|l|r|r|r|c|}
\hline Objective & Unweighted & Weighted & $\boldsymbol{\chi}^{\mathbf{2}}$ (weighted versus unweighted) & p-value \\
\hline Wildlife habitat and management & $73.5 \%$ & $77.2 \%$ & 0.3685 & 0.5438 \\
\hline Restoration of native forest cover & $69.6 \%$ & $71.8 \%$ & 0.1168 & 0.7325 \\
\hline Local environment protection (soil, water, air) & $51.5 \%$ & $50.5 \%$ & 0.0200 & 0.8875 \\
\hline Climate change mitigation & $49.0 \%$ & $50.3 \%$ & 0.0338 & 0.8541 \\
\hline Shade, buffer, or windbreak & $48.7 \%$ & $44.6 \%$ & 0.3377 & 0.5612 \\
\hline Legacy to descendants & $43.9 \%$ & $47.0 \%$ & 0.1938 & 0.6598 \\
\hline Future income from wood products & $8.8 \%$ & $10.2 \%$ & 0.1140 & 0.7357 \\
\hline
\end{tabular}


farm owners were more likely to plant trees for this reason. However, farm owners were not statistically more likely to identify shelter breaks as a motivation for planting trees $\left(\chi^{2}=0.44, p=0.51\right)$.

The term "family forests" highlights the role that family legacy is thought to play in motivating tree planting (Côté, et al., 2015). About four in ten respondents to our survey indicated that legacy was a reason for them to plant trees (43.9\%). Almost half of respondents aged 55+ reported legacy as a motivation $(48.9 \%)$ compared to $37.8 \%$ of younger respondents $\left(\chi^{2}=7.03, p=.008\right)$.

Only one in ten respondents (8.8\%) was motivated by future income to plant trees. Men were twice as likely to report an interest in future income from wood products $(11.3 \%)$ compared to women $(4.0 \%)$, a statistically significant difference $\left(\chi^{2}=5.82, p=.02\right)$. Farm owners were significantly more likely to report planting trees to generate future income (11.5\%) compared to non-farm owners $\left(6.4 \%, \chi^{2}=4.41, p\right.$ $=.04)$.

The motivations reported by property owners that had completed an afforestation project were similar to those identified by applicants to a Forests Ontario program (MacDonald et al., 2018). Specifically, most applicants indicated that they wished to plant trees to attract wildlife to their property (57.5\%; MacDonald et al., 2018). Applicants to the 50 Million Tree Program were interested in adding native forest cover (54.5\%), protecting the local environment (46.1\%), providing shade on their property (40.7\%) and helping to mitigate climate change (35.9\%). Only $12.5 \%$ of applicants indicated that they expected to generate income. The survey of applicants suggested that $28.1 \%$ wished to leave a legacy, compared to around half of those that completed a project.

\subsection{Experienced Benefits of Planting Trees}

Overall, $67 \%$ of respondents reported enhanced well-being and enjoyment of their property since planting trees, compared to $24.5 \%$ who noticed an increase in wildlife, and $15 \%$ who indicated that soil, water or air quality had improved since planting trees. Chi-square tests indicated that motivations and benefits were not independent. Respondents who planted trees to improve wildlife habitat were more likely to report an improvement to their property in this regard $(27.0 \%)$ compared to those without wildlife habitat as a motivation $\left(11.8 \%, \chi^{2}=9.46\right.$, $p=.002$ ). Also, respondents who gave improvement of the local environment as a reason for planting trees were significantly more likely to report positive improvements in this regard following tree planting $(19.7 \%)$ compared to $9.2 \%$ of those that did not expressly plant trees for this reason $\left(\chi^{2}=10.35, p\right.$ $=.001$ ).

Reported increases in wildlife and improvements in the local environment were related to how much time had elapsed since planting trees. In contrast, participants' well-being reportedly improved more immediately after tree planting. Figure 2 illustrates the percentage of respondents who reported an impact of tree planting by tree age. For wildlife impacts, we included respondents who reported wildlife habitat as a reason for tree planting. Similarly, environmental impacts in Figure 2 are presented for those land owners that planted trees in order to improve the local environment.

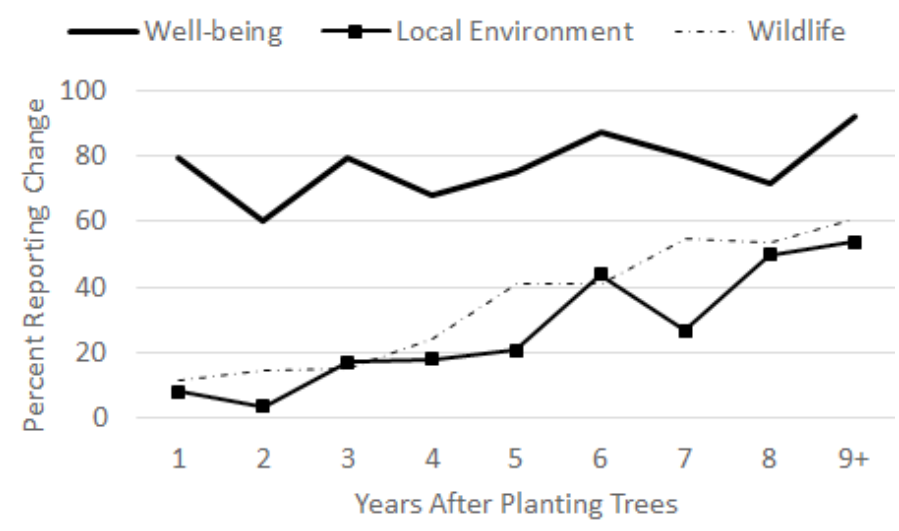

Figure 2: Changes in Property Reported by Participants by Tree Age

A summary of the results of the logistic regression (PROC GENMOD) analysis is presented in Table 3 below. The coefficient for TreeAge was significant and positive, indicating that generally benefits increased with time since planting trees $(0.3388, z=6.61$, $p<0.0001)$. As well, the coefficients for Well-being and Wildlife were both positive and significant, meaning that these benefits were more likely to be reported compared to Local Environment benefits (i.e., the default benefit). The interaction term TreeAge * Well-being was significant, indicating that the relationship between Tree Age and well-being 
differs from that of Tree Age to the other benefits $(-0.2277, z=-3.59, p=0.0003)$. The interaction of wildlife benefits and tree age was not significant.

Table 3: Analysis of GENMOD regression coefficients, standard error estimates, $z$ scores and $p$-values

\begin{tabular}{|l|r|r|r|r|}
\hline Parameter & Coefficient & $\begin{array}{c}\text { Standard } \\
\text { Error }\end{array}$ & z-score & $\operatorname{Pr}\rangle|\mathbf{Z}|$ \\
\hline Intercept & -3.3154 & 0.3000 & -11.05 & $<.0001$ \\
\hline TreeAge & 0.3388 & 0.0513 & 6.61 & $<.0001$ \\
\hline Well-being & 3.7579 & 0.3289 & 11.42 & $<.0001$ \\
\hline Wildlife & 0.7214 & 0.3241 & 2.23 & 0.0260 \\
\hline $\begin{array}{l}\text { TreeAge * } \\
\text { Well-being }\end{array}$ & -0.2277 & 0.0634 & -3.59 & 0.0003 \\
\hline $\begin{array}{l}\text { TreeAge * } \\
\text { Wildlife }\end{array}$ & -0.0042 & 0.0603 & -0.07 & 0.9448 \\
\hline
\end{tabular}

Comparing predictions and observed values, the model was able to successfully predict whether an improvement was reported $77.6 \%$ of the time.

\section{Conclusions}

In summary, this survey with 570 participants in tree planting programs indicates that, consistent with a previous intake survey (MacDonald, et al., 2018), the goal of creating habitat for wildlife was a major motivator for planting trees, as well as a desire to restore native tree species. Reported benefits were significantly related to how long new trees had been in the ground. On the other hand, well-being and property enjoyment were less strongly related to tree age, and showed improvement for all tree age classes. The results of the survey indicated that experiences with the program were highly positive, with over two-thirds of respondents reporting an increase in well-being since planting trees.

Understanding the characteristics of participants in tree planting programs is important, because individuals that have previously planted trees are most likely to do so in the future (Ruseva et al., 2015). Future research should continue to track former participants in this tree planting program to determine how long after tree planting most respondents report a significant improvement in wildlife and in the local environment. Future follow-up with partic- ipants could explore changes in attachment to the land as a function of time elapsed since tree planting. As this study concluded, planting trees increased owners' well-being and enjoyment of their property. Does attachment to one's property show the same pattern as well-being and enjoyment (an immediate improvement) or does attachment increase as changes in wildlife and environment are experienced? A future survey could also attempt to reach out to early participant groups by mail to explore to what extent wildlife and environmental benefits were realized more than ten years after tree planting. From an implementation perspective, the study indicates that emphasizing benefits to wildlife when promoting tree planting programs may be effective to help motivate private land owners to convert parcels of land to forest.

\section{Acknowledgements}

We would like to thank two anonymous reviewers for their insightful comments and useful analytic suggestions. Also, we are grateful to John Pedlar, Kevin Lawrence and Meghan Sloane for their editorial and technical assistance, comments and suggestions on earlier drafts of this manuscript. All remaining errors are the responsibility of the authors, exclusive of their respective organizations.

\section{References}

ArborVitae Environmental Services Ltd., Woodrising Consulting Inc., and P. Duinker 1999. Estimating the carbon sequestration benefits of afforestation in Ontario, Quebec, and the Atlantic provinces. National Climate Change Process Joint Forest Sector Table/Sinks Table Afforestation Studies \#2 and \#3 Ottawa, ON, 91 pp.

Borczon, E.L. 1982. Evergreen Challenge: The Agreement Forest Story. Ontario Ministry of Natural Resources. $60 \mathrm{p}$. 
Butler, B.J., Hewes, J.H., Dickinson, B.J., Andrejczyk, K., Butler, S.M., \& Markowski-Lindsay, M. 2016. Family forest ownerships of the United States, 2013: Findings from the USDA forest service's national woodland owner survey. Journal of Forestry 114, 638-647. DOI: 10.5849/jof.15-099

Butler, B.J. 2008. Family forest owners of the United States, 2006. Gen. Tech. Rep. NRS-27. Newtown Square, PA: US Department of Agriculture, Forest Service, Northern Research Station. 72 p. DOI: 10.2737/NRS-GTR-27

Butler, B.J., Leatherberry, E.C., Best, C., Kilgore, M.A., Sampson, R.N., \& Larson, K. 2004. America's family forest owners. Journal of Forestry 102, 4-14. DOI: 10.1093/jof/102.7.4

Butt, S., Ramprasad, P., Fenech, A. 2005. Changes in the landscape of southern Ontario Canada since 1750. Integrated Mapping Assessment 83-92. https://www.islandscholar.ca/islandora/ object/ir\%3A4185/datastream/PDF/view (Date: 03.04.2019).

Carmichael, C., \& McDonough, M. 2018. The trouble with trees? social and political dynamics of street tree-planting efforts in Detroit, Michigan, USA. Urban Forestry \& Urban Greening 31, 221-229. DOI: 10.1016/j.ufug.2018.03.009

Cherry, M. 2001. Options for allocation of tree planting stock for afforestation in ontario with anticipated climate change. Forest Research Information Paper No 148. Report prepared for the Ontario Ministry of Natural Resources. ISBN 0-7794-2260-0

Conway, T.M. 2016. Tending their urban forest: Residents' motivations for tree planting and removal. Urban Forestry and Urban Greening 17, 23-32. DOI: 10.1016/j.ufug.2016.03.008
Cook, C., Heath, F., \& Thompson, R. L. 2000. A meta-analysis of response rates in Web- or internet-based surveys. Educational and Psychological Measurement 60, 821-836. DOI: 10.1177/00131640021970934

Côté, M., Gilbert, D., \& Nadeau, S. 2015. Characterizing the profiles, motivations and behaviour of Quebec's forest owners. Forest Policy and Economics 59, 83-90. DOI: 10.1016/j. forpol.2015.06.004

Elliott, KA. 1998. The forests of southern Ontario. The Forestry Chronicle 74(6):850-854. https:// pubs.cif-ifc.org/doi/pdf/10.5558/tfc74850-6 (Date: 03.04.2019).

Forests Ontario. 2017. Forests Ontario Commends the Ontario Government for Increasing Funding for Tree Planting Program. https://www.newswire. $\mathrm{ca} /$ news-releases/forests-ontario-commendsthe-ontario-government-for-increasing-fundingfor-tree-planting-program-642254903.html (Date: 05.12.2018).

Government of Ontario. 2007. Go Green: Ontario's Action Plan on Climate Change. http://www.climateontario.ca/doc/ workshop/2011LakeSimcoe/Ontarios\%20Go\%20 Green\%20Action\%20Plan\%20on\%20Climate\%20 Change.pdf (Date: 05.12.2018).

Hartig, T., Evans, G.W., Jamner, L.D., Davis, D.S., \& Gärling, T. 2003. Tracking restoration in natural and urban field settings. Journal of Environmental Psychology 23, 109-123. DOI: 10.1016/S02724944(02)00109-3

Keniger, L.E., Gaston, K.J., Irvine, K.N., \& Fuller, R.A. 2013. What are the benefits of interacting with nature? International journal of environmental research and public health 10, 913-935. DOI: 10.3390/ijerph10030913 
MacDonald, H., McKenney, D.W., Pedlar, J.H., Hope, E.S., McLaven, K., \& Perry, S. (2018). Adoption influences in Ontario's 50 million tree program. Forestry Chronicle 94(3), 221-229. DOI: 10.5558/ tfc2018-035

Messer, B.L., \& Dillman, D.A. 2011. Surveying the general public over the internet using addressbased sampling and mail contact procedures. Public opinion quarterly 75, 429-457. DOI: $10.1093 / \mathrm{poq} / \mathrm{nfr} 021$

Ontario Ministry of Natural Resources 2001. Critical review of historical and current tree planting programs on private lands in Ontario, project done in partial completion of project CC-109.

Ross-Davis, A.L., Broussard, S.R., Jacobs, D.F., Davis, A.S. 2005. Afforestation motivations of private landowners: an examination of hardwood tree plantings in Indiana. Northern Journal of Applied Forestry 22(3):149-153. DOI: 10.1093/ njaf/22.3.149

Ruseva, T.B., Evans, T.P., Fischer, B.C. 2015. Can incentives make a difference? Assessing the effects of policy tools for encouraging treeplanting on private lands. Journal Environmental Management 155, 162-170. DOI: 10.1016/j. jenvman.2015.03.026

Van den Berg, A.E., Koole, SL., \& Van der Wulp, N.Y. 2003. Environmental preference and restoration:(How) are they related? Journal of Environmental Psychology 23, 135-146. DOI: 10.1016/S0272-4944(02)00111-1 